\title{
Effects of Young's Modulus on Disc Brake Squeal using Finite Element Analysis
}

\author{
Ali Belhocine \\ Mechanical Engineering Dept., USTO Oran University, B.P 1505 El - Mnaouer, USTO 31000, Oran, Algeria \\ Nouby M. Ghazaly \\ Mechanical Engineering Dept., Faculty of Engineering, South Valley University, Qena-83523, Egypt
}

(Received 9 July 2014; accepted 24 June 2016)

This paper is concerned with the disc brake squeal problem of passenger cars. The objective of this study is to develop a finite element model of the disc brake assembly in order to improve the understanding of the influence of Young's modulus on squeal generation. A detailed finite element model of the whole disc brake assembly that integrates the wheel hub and steering knuckle is developed and validated by using experimental modal analysis. Stability analysis of the disc brake assembly is conducted to find unstable frequencies. A parametric study is carried out to look into the effect of changing Young's modulus of each brake's components on squeal generation. The simulation results indicate that Young's modulus of the disc brake components plays an important role in generating the squeal noise.

\section{INTRODUCTION}

Passenger cars have historically been one of the essential methods of ground transportation for people who want to move from one place to another. The braking system acts as one of the most fundamental safety-critical components in modern passenger cars. Therefore, the braking system of a vehicle is a significant system, especially when the vehicles are slowing down or stopping. Due to the braking operation, the brake system generates an unwanted high frequency sound called squeal noise. It occurs in the frequency range between 1 and $16 \mathrm{kHz}$ and leads to customer dissatisfaction and increases warranty costs. Although substantial research has been conducted into predicting and eliminating brake squeal since the 1930s, it is still rather difficult to predict its occurrence. ${ }^{1}$ As described in some of the recent review papers, ${ }^{2-5}$ theories on brake squeal mechanisms have been put forward on six major classes: stickslip, sprag-slip, negative friction velocity slope, hammering excitation, splitting the doublet modes, and mode coupling of structures. These mechanisms are essential for better understanding of squeal noise.

In recent years, the finite element (FE) method has become the preferred method to study brake squeals. The capabilities of FE models, with a huge number of freedom, have enabled an accurate representation of the brake system. The analysis of disc brake squeal using the FE model could reflect each detail of the brake design, while this demanded a lot of effort to do significant changes in the geometry of components. ${ }^{6}$ Due to a general lack of confidence in FE models, the dynamic testing of structures had become a standard procedure for model validation and updating. Over the past years, modal testing and analysis had become a fast- developing technique for the experimental evaluation of the dynamic properties of structures. ${ }^{7}$ Several types of analyses had been performed on disc brake systems through FEA, in an attempt to understand the noise and to develop a predictive design tool. There were two numerical methods that are used to study this problem: transient dynamic analysis ${ }^{8,9}$ and complex eigenvalue analysis. ${ }^{10-13}$ Currently, the complex eigenvalue method is the most commonly preferred method. Generally, the existence of complex eigenvalues with positive real parts indicated the presence of instability and the magnitude of the real part is used to represent the level of system instability or squeal propensity.

Reduction and elimination of the brake squeal was an important task for the improvement of the vehicle passengers' comfort. Many researchers, in their studies on brake systems tried to reduce squeal noise by changing the factors associated with the brake squeal. For example, Liles ${ }^{14}$ found that shorter pads, damping, a softer disc, and a stiffer back plate could reduce squeal, while in contrast, a higher friction coefficient and wear of the friction materials were prone to squeal. Lee et al. ${ }^{15}$ reported that reducing back plate thickness led to less uniform contact pressure distributions and consequently increased the squeal propensity. Kung et al. ${ }^{10}$, in their simulations, showed that instability of the disc brake was dependent upon a range of disc Young's modulus. Liu et al. ${ }^{12}$ commented that the squeal could be reduced by decreasing the friction coefficient, increasing the stiffness of the disc, using damping material on the back of the pads, and modifying the shape of the brake pads. Recently, Nouby et al. ${ }^{16}$ introduced a combined approach of complex eigenvalue analysis (CEA) and designed experiments to get optimal design for the brake system. They reported that the brake squeal propensity could be reduced by increasing Young's modulus of the back plate and by modifying the shape of the friction material by adding chamfer and slots.

In FEA, several researchers varied the geometric details of the brake assembly model. For instance, some researchers ${ }^{12,17}$ considered only the disc brake and two pads. Zhu et al. ${ }^{18}$ added the finger and piston to the FE model. Dai and Teik ${ }^{19}$ developed a FE model that consisted of a rotor, a caliper, a mounting bracket, a piston, and brake pads to analyze the design of the disc brake pad structure for squeal noise reduction. Some authors ${ }^{20-22}$ used a more detailed FE model, which consisted of a disc, a piston, a caliper, a carrier, piston and finger pads, two bolts and two guide pins.

An extension of the FE models discussed earlier in this work 


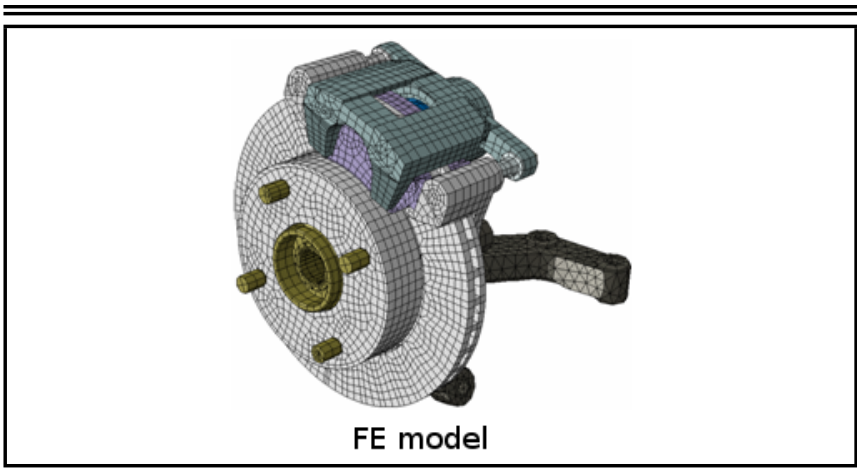

Figure 1. A commercial disc brake corner.

on a three-dimensional model of a validated FE model of the disc brake assembly that incorporated the wheel hub and steering knuckle was considered. Experimental modal analysis of a disc brake system was first used to develop and validate the FE model to improve accuracy of simulation results. Then, stability of the disc brake assembly with frequencies ranging from $1 \mathrm{kHz}$ to $10 \mathrm{kHz}$ was examined by using FE software ABAQUS. A preliminary FE simulation was carried out to predict unstable frequencies by applying complex eigenvalue analysis to the FE model. Finally, the parametric study as a guide was conducted to evaluate the influence of the Young's modulus on the disc brake components.

\section{FINITE ELEMENT MODEL}

A detailed three dimensional FE model of a vented disc brake assembly that had been used in this work is shown in Fig. 1. All disc brake system components, except a rubber seal (attached to the piston), two rubber washers (attached to the guide pins), and the pad insulator, have been included in the model. The FE model consisted of a disc, a piston, a caliper, an anchor bracket, a wheel hub, a steering knuckle, piston and finger pads, two bolts, and two guide pins. All the disc brake components were modeled in order to achieve as accurate a representation of a real disc brake as possible.

The FE model uses up to 19,000 solid elements and approximately 78,000 Degrees of Freedom (DOFs). The disc, brake pads, piston, wheel hub, guide pins, and bolts were developed by using 8-node (C3D8) linear solid elements, while other components were developed by using a combination of 8 node (C3D8), 6-node (C3D6) and 4-node (C3D4), linear solid elements. Details for each of the components are given in Table 1 .

In the brake assembly FE model, all the disc brake components were integrated together to form an assembly model and all the boundary conditions and component interfaces were considered. Contact interaction between disc brake components was represented by a combination of node-to- surface and surface-to-surface contact elements. The surface of the disc was defined as the master surface, since it had a coarser mesh than the pad and the disc was made of a stiffer material. The pad was therefore treated as the slave surface. This enables the slave surface to potentially contact the entire master surface.

\section{VALIDATION OF THE FE MODEL}

The purpose of this section was to ensure that accuracy of the dynamical properties of the FE model agreed with those

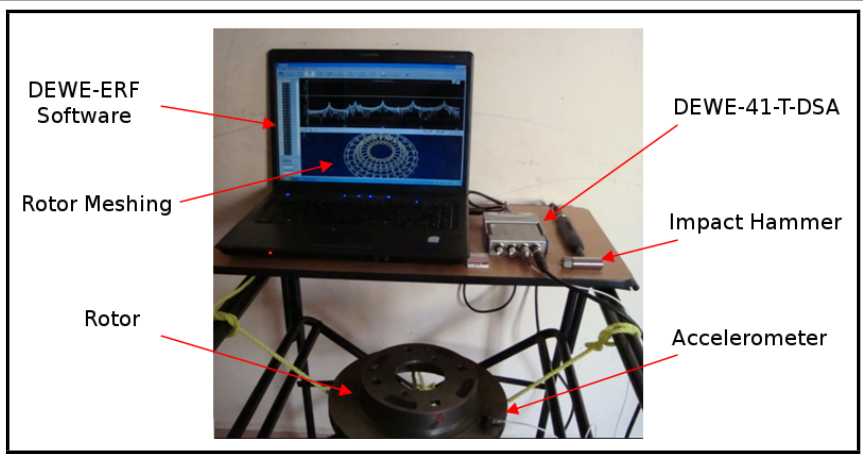

Figure 2. Experimental Modal Analysis set-up.

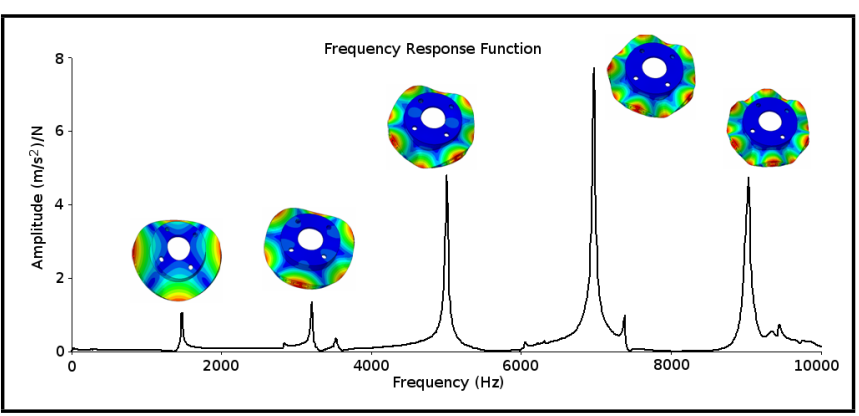

Figure 3. FRF measured for the brake rotor.

of the physical component. Two validation stages were established (i.e., modal analysis at component and assembly levels). Frequency Response Functions (FRF) measurements using impact hammer and accelerometer were recorded by DEWE/FRF software. Fig. 2 shows the experimental modal analysis set-up.

First, modal analysis at the component level was carried up to frequencies of $10 \mathrm{kHz}$. The FRF result for brake rotor was performed at free-free boundary conditions, as shown in Fig. 3. An accurate representation of the component model formed one of the validation stages for good squeal correspondence between experiments and predictions. In order to correct the predicted frequencies with the experimental results, an FE updating was used to reduce the relative errors between the two sets of results by tuning material. The baseline material properties of the disc brake components after FE updating are listed in Table 2. It was found that the predicted natural frequencies for brake rotor was quite close to those obtained in the measured data, as listed in Table 3. Similarly, validation of the other brake components was performed. A good agreement between the predicted results and the measured data for the brake components was also found, as listed in Appendix A.

The second validation stage was to perform dynamic characteristics of the complete assembly with boundary conditions. In experimental modal analysis, the individual components were fixed on a brake test rig under applied pressure of $1 \mathrm{MPa}$. Fig. 4 shows the results of the FRF measured for the disc brake assembly. A similar condition was also applied to the FE brake assembly model. In this validation, measurements were taken on the disc, as it had a regular shape than the other components. The analysis results show that a good agreement was found between the predicted results and the measured data, as shown in Table 4. 
Table 1. Element details of the disc brake components.

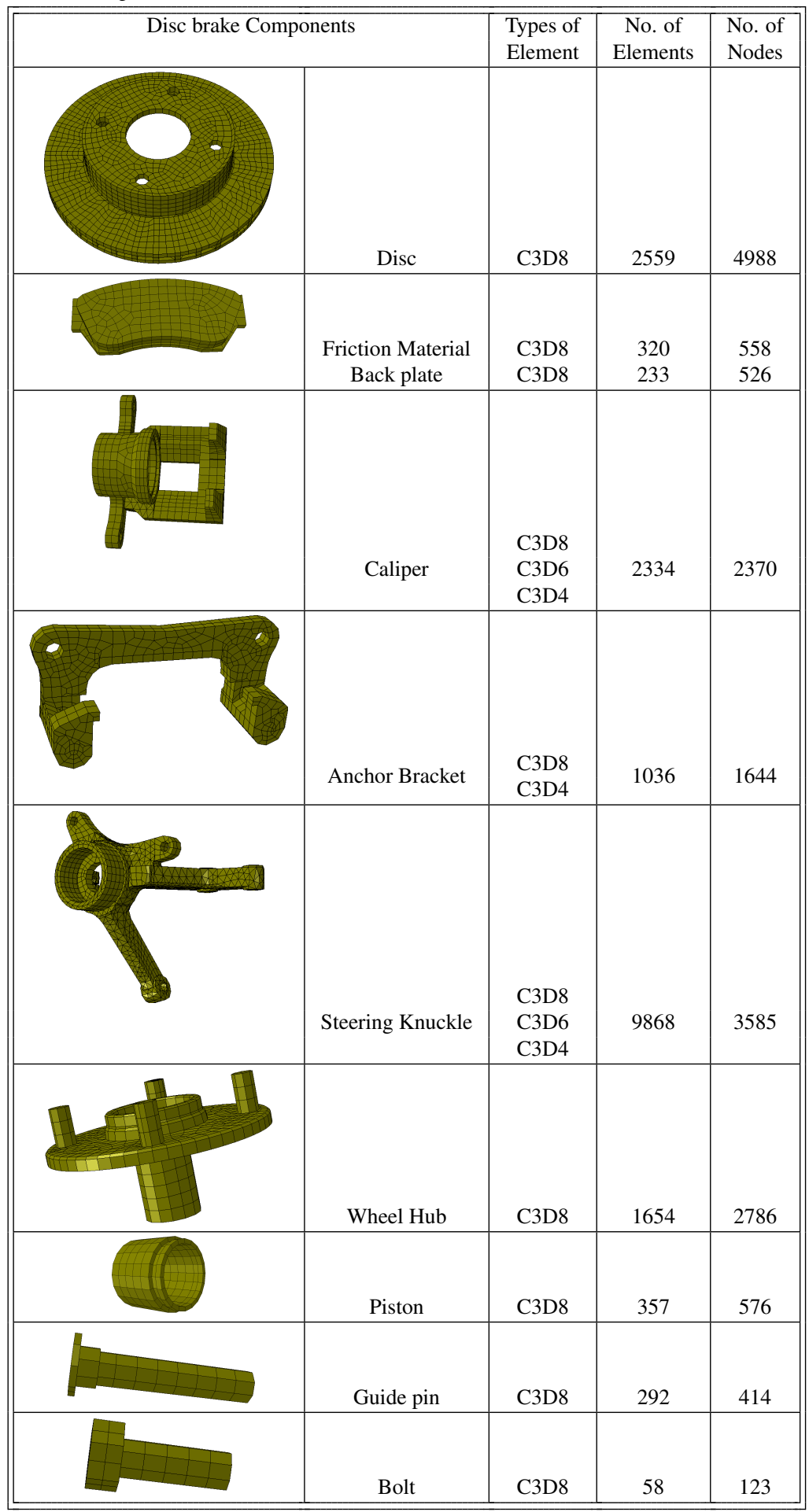

Table 2. Material properties of the disc brake component.

\begin{tabular}{||c|c|c|c||}
\hline Components & $\begin{array}{c}\text { Density } \\
\left(\mathrm{kg} \mathrm{m}^{-3}\right)\end{array}$ & $\begin{array}{c}\text { Young's } \\
\text { Modulus (GPa) }\end{array}$ & Poisson's ratio \\
\hline Disc & 7155 & 125 & 0.23 \\
\hline Friction material & 2045 & 2.6 & 0.34 \\
\hline Back plate & 7850 & 210 & 0.30 \\
\hline Caliper & 7005 & 171 & 0.27 \\
\hline Anchor Bracket & 7050 & 166 & 0.27 \\
\hline Steering Knuckle & 7625 & 167 & 0.29 \\
\hline Wheel Hub & 7390 & 168 & 0.29 \\
\hline Piston & 8018 & 193 & 0.27 \\
\hline Guide pin & 2850 & 71 & 0.30 \\
\hline Bolt & 7860 & 210 & 0.30 \\
\hline
\end{tabular}

Table 3. Comparisons between the predicted results and measured data for the brake rotor.

\begin{tabular}{|c|c|c|c|c|c|}
\hline Mode & 1 & 2 & 3 & 4 & 5 \\
\hline Exp. (Hz) & 1464 & 3198 & 4992 & 6957 & 9020 \\
\hline FEA (Hz) & 1453 & 3225 & 5062 & 7067 & 9170 \\
\hline Error (\%) & -0.7 & 0.8 & 1.4 & 1.5 & 1.6 \\
\hline
\end{tabular}

Table 4. Comparisons between the predicted results and measured data for brake assembly.

\begin{tabular}{|c|c|c|c|c|c|}
\hline Mode & 1 & 2 & 3 & 4 & 5 \\
\hline Exp. (Hz) & 1611 & 3222 & 5065 & 7043 & 9130 \\
\hline FEA (Hz) & 1562 & 3174 & 5184 & 6597 & 9452 \\
\hline Error (\%) & -3 & -1.4 & 2.3 & -6.3 & 3.5 \\
\hline
\end{tabular}




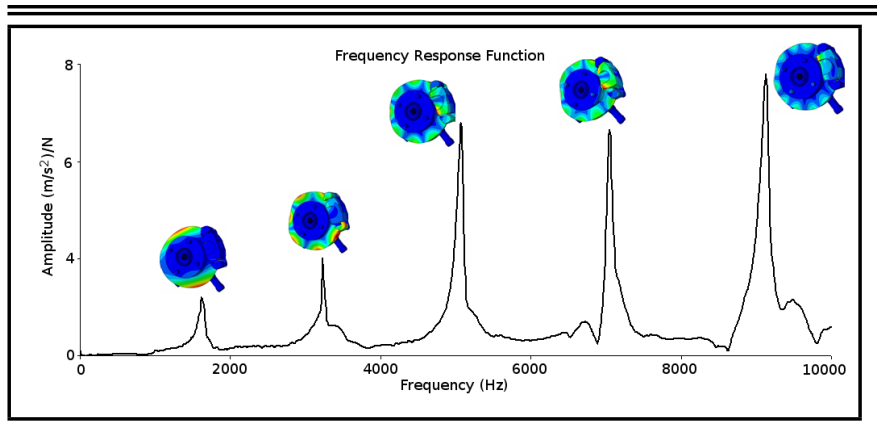

Figure 4. FRF measured for the disc brake assembly.

\section{CONTACT ANALYSIS}

In recent years, the complex eigenvalue analysis has become the preferred method to investigate the stability of brake system modes. Complex eigenvalues usually result from the frictional coupling of brake components due to the off-diagonal terms that arise in the stiffness matrix of the system, causing it to be unsymmetrical. The positive real parts of the complex eigenvalues indicated the degree of instability of the disc brake assembly and reflected the likelihood of squeal occurrence. Complex eigenvalues with positive real parts were identified as unstable modes and corresponding frequencies, which always appeared in complex conjugate pairs. The complex eigenvalue analysis in ABAQUS was used to determine instability in disc brake assembly. ${ }^{14}$ In order to perform the complex eigenvalue analysis using ABAQUS, four main steps were required. They are as follows:

- Nonlinear static analysis for applying brake-line pressure.

- Nonlinear static analysis to impose rotational speed on the disc.

- Normal mode analysis to extract natural frequency of undamped system.

- Complex eigenvalue analysis that incorporated the effect of friction coupling.

The complex eigenvalue analysis was examined between $1 \mathrm{kHz}$ and $10 \mathrm{kHz}$ by using the ABAQUS version 6.8 with brake-line pressure of $0.7 \mathrm{MPa}$, a rotational speed of $5 \mathrm{rad} / \mathrm{s}$ to assess the brake propensity as the friction coefficient values. The influence of friction coefficient of the pad-rotor interface was performed. The unstable modes for varying $\mu$ from 0.1 to 0.5 were plotted as real parts versus frequency in Fig. 5 to illustrate how the instability increases with friction level. It was found that the propensity for squeal increases with higher coefficients of friction. This was because the higher coefficient of friction causes the variable frictional forces to be higher resulting in the tendency to excite greater number of unstable modes.

In this study, the baseline model for investigating the effects of elastic modulus of the main disc brake components on squeal generation was considered at $=0.5$. It was found that at $=0.5$, there were five unstable frequencies predicted at $2777 \mathrm{~Hz}, 7573 \mathrm{~Hz}, 8530 \mathrm{~Hz}, 9453 \mathrm{~Hz}$, and $9722 \mathrm{~Hz}$, as shown in Fig. 6.

\section{PARAMETRIC STUDIES}

The aim of this section is to propose parametric studies in order to examine the effects of material properties of the disc

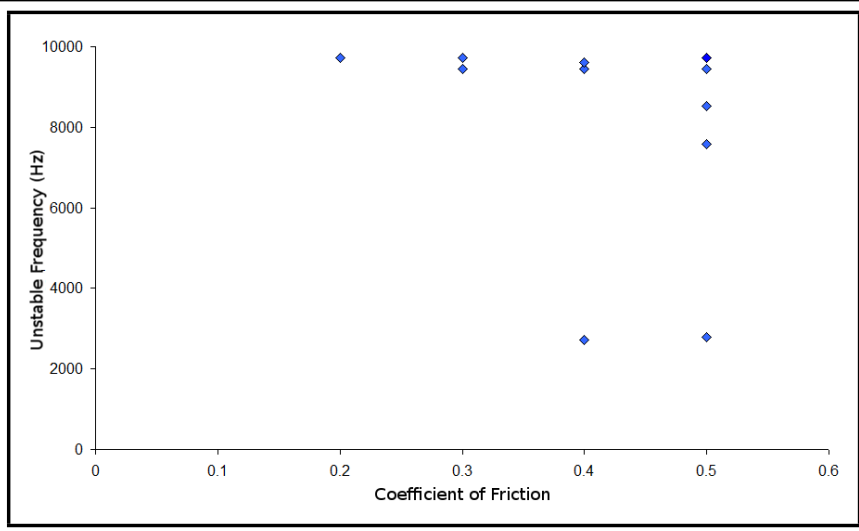

Figure 5. Predicted unstable frequencies for varying coefficient of friction values.

brake components on disc brake squeal generation. Fieldhouse and $\mathrm{Stee}^{23}$ suggested that the source of a noisy brake may lie as much in basic mechanical design as inappropriate material choice. When the components were in an assembly, there may have been a significant redistribution of stiffness and mass throughout the structure if a component's material property was changed. This in turn will change the natural frequencies of the assembly as a whole as well as potentially varying the strain energy distribution during vibration. As a consequence, it was necessary to design the entire brake components so that their natural frequencies in the audible range were as isolated as possible to avoid mode coupling. In this study, the effect of elastic modulus for disc brake components was examined using parametric studies in order to reduce squeal generation. Theoretically, this was thought to have been achieved when either the positive real parts of eigenvalues of the baseline model were reduced or the predicted unstable frequencies in the baseline model totally disappeared. Details of the parametric study of Young's modulus of the disc brake components are discussed below.

\subsection{Influence of Rotor Young's Modulus}

Disc brake rotors in wide use today are made of gray cast irons, because they have acceptable thermal properties, sufficient mechanical strength, satisfactory wear resistance, and good damping properties, they are cheap and relatively easy to cast. Gray cast irons differ somewhat to steels and most other structural metals in that the Young's modulus could be varied significantly by changing carbon equivalent. This allowed the rotors to be manufactured with Young's modulus that runs from below $100 \mathrm{GPa}$ through to approximately $140 \mathrm{GPa}$.

In this section, variation of Young's modulus of the brake rotor from $100 \mathrm{GPa}$ to $140 \mathrm{GPa}$ was simulated. Where the baseline Young's modulus of the disc is $125 \mathrm{GPa}$. The density and Poisson's ratio of these variants was assumed to be as the same as the baseline model. Fig. 7 presents the real parts versus frequency for different Young's modulus of the rotor. From the simulation results, it was found that increasing Young's modulus of the rotor to $140 \mathrm{GPa}$ was capable of eliminating positive real parts for unstable frequencies of $2777 \mathrm{~Hz}, 8530 \mathrm{~Hz}$, and $9722 \mathrm{~Hz}$. On the other hand, by reducing Young's modulus of the rotor to $100 \mathrm{GPa}$, a new unstable frequency had appeared at approximately $5100 \mathrm{~Hz}$. Additionally, the number of unstable frequencies was unchanged, but their magnitudes were increased, especially at frequencies of $2777 \mathrm{~Hz}, 7573 \mathrm{~Hz}$, $9453 \mathrm{~Hz}$, and $9722 \mathrm{~Hz}$. In theory, the higher positive real parts, 


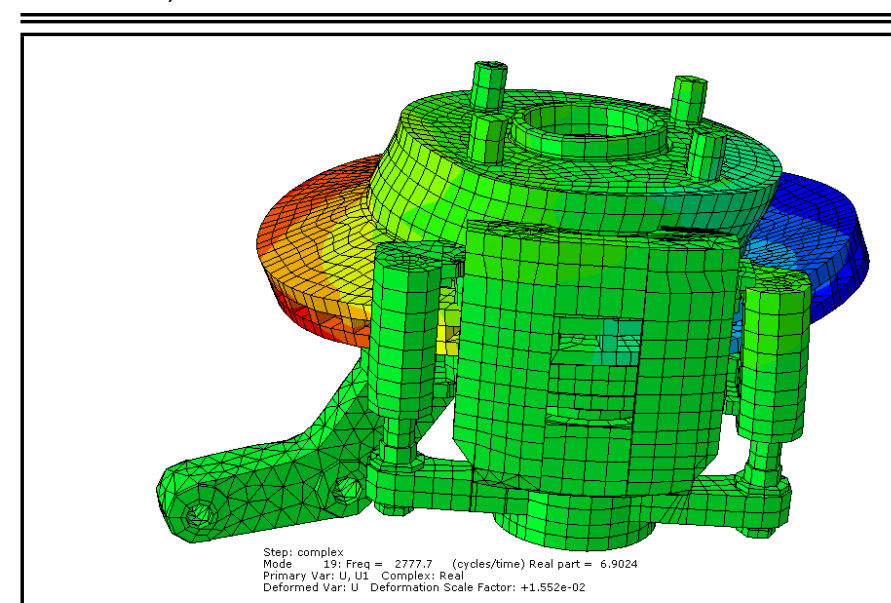

(a)

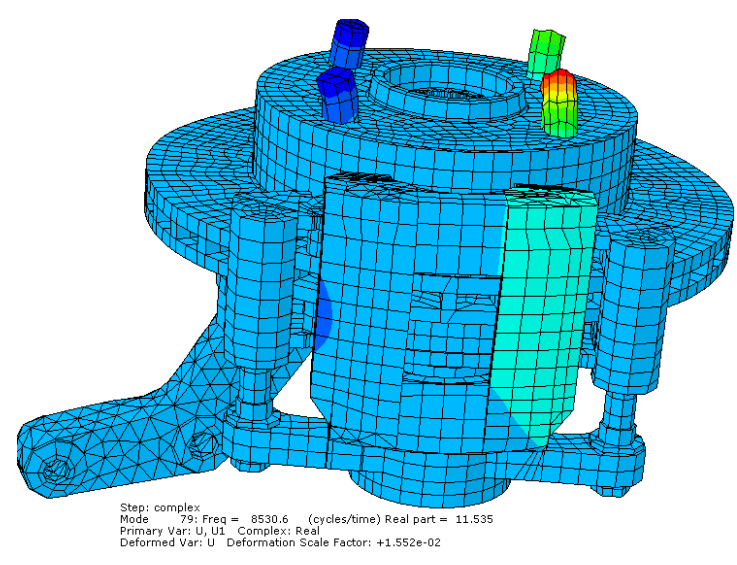

(c)

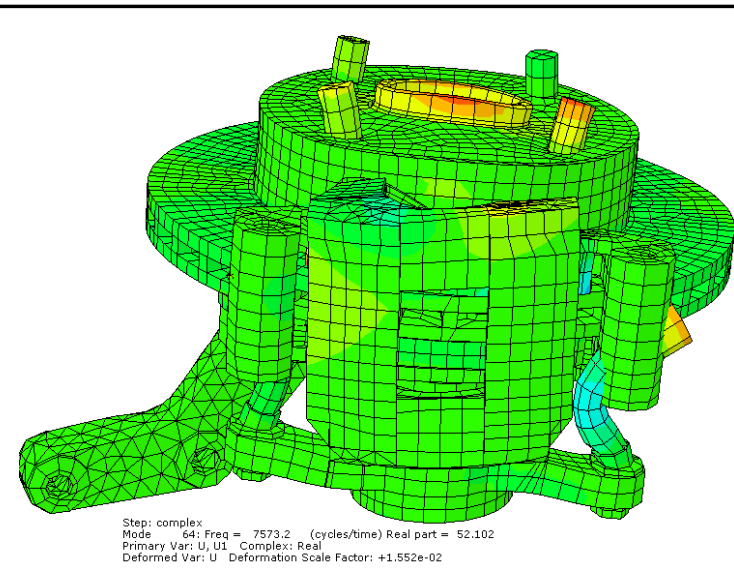

(b)

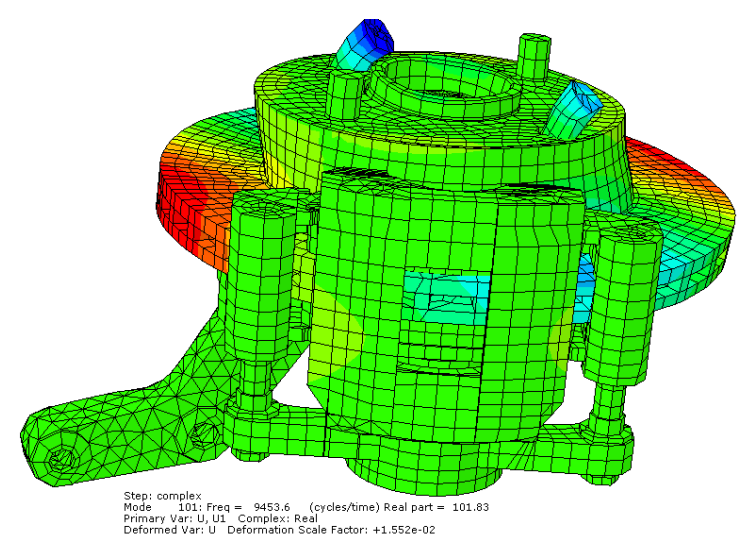

(d)

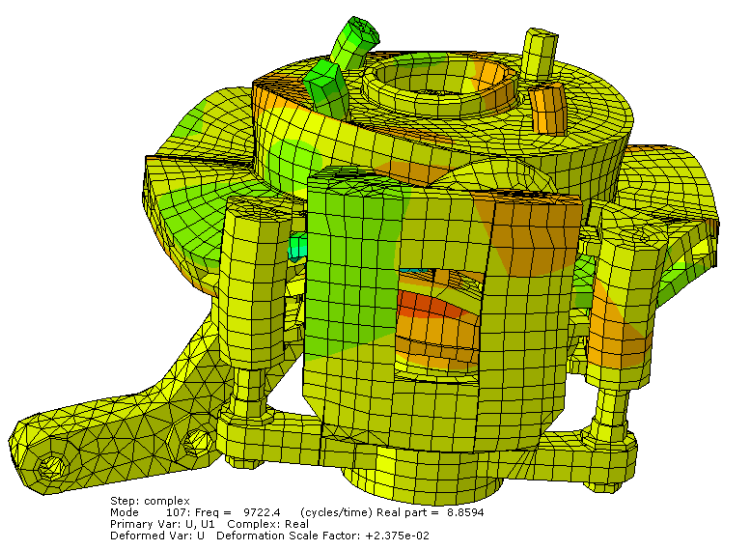

(e)

Figure 6. Predicted unstable frequencies of the disc brake corner for the baseline model at $=0.5$ : (a) $2777 \mathrm{~Hz}$ (b) $7573 \mathrm{~Hz}$ (c) $8530 \mathrm{~Hz}$ (d) $9453 \mathrm{~Hz}$ and (e) $9722 \mathrm{~Hz}$.

the more tendency the squeal to occur. Overall, it was observed that the rotor Young's modulus had a significant effect on the stability of the system. Increasing Young's modulus of the disc may be reducing the brake squeal generation. Similar evaluations have been carried out by Liu et al. ${ }^{12}$ Also, Dunlap ${ }^{24}$ reported that increased rotor stiffness was directionally correct for reduction in squeal propensity.

\subsection{Influence of Friction Material Young's Modulus}

It was necessary to investigate the effect of the friction material stiffness on the squeal propensity for the design of a quiet brake system, since changes in the pad stiffness could alter the mode coupling between the pads and rotor. In this section, variation of Young's modulus of the friction material from $0.5 \mathrm{GPa}$ to $4 \mathrm{GPa}$ was simulated. These values of Young's modulus were in the range readily attained within brake pads available in the market. ${ }^{25}$ Where the baseline Young's modulus of the disc is $2.6 \mathrm{GPa}$. The other properties, such as Poisson's ratio and density of these variants, were assumed to be the same as the baseline model. Similarly, Young's modulus of other components was also unchanged. Having simulated the variation of Young's modulus of the friction material, it can be seen from Fig. 8 that increasing Young's modulus of the friction material to $4 \mathrm{GPa}$ was capable of eliminating positive 


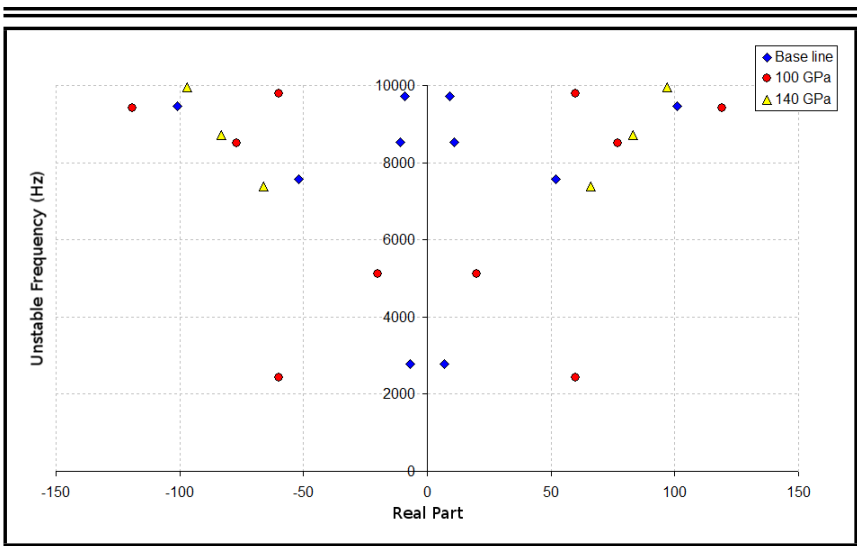

Figure 7. The Effect of Young's modulus of the rotor on the brake squeal generation.

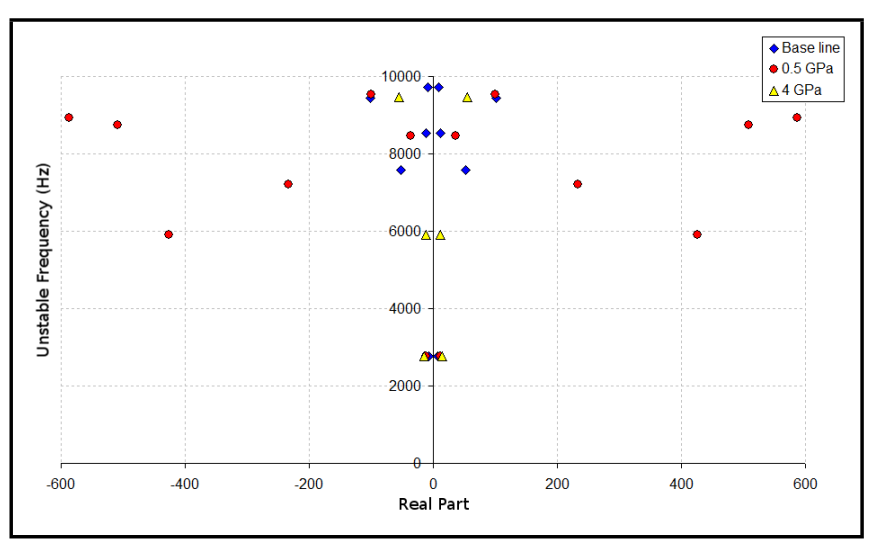

Figure 8. The effect of Young's modulus on the friction material on the brake squeal generation.

real parts for unstable frequencies of $7573 \mathrm{~Hz}, 8530 \mathrm{~Hz}$, and $9722 \mathrm{~Hz}$, and of reducing the positive real part for unstable frequency of $9453 \mathrm{~Hz}$. On the other hand, reducing Young's modulus of the friction material to $0.5 \mathrm{GPa}$ by increasing the overall number of unstable frequencies and the real parts especially at high frequency squeal.

From the predicted results, it can be concluded that stiffer friction material causes the system to be more stable and reduces squeal generation. This finding seems to agree with that from Liles. ${ }^{14}$ Also, Papinniemi ${ }^{21}$ reported that increasing pad Young's modulus reduced the overall number of unstable modes and indicated that the overall system stability would be enhanced with higher modulus pads. The most probable physical explanation for this would be a reduction in pad deformation.

\subsection{Influence of Anchor Bracket Young's Modulus}

The anchor bracket was made from ductile cast iron component that was used for housing the caliper and pads in brake assembly. This anchor bracket was attached to the steering knuckle. The baseline Young's modulus of the bracket was $166 \mathrm{GPa}$. In this section, the baseline Young's modulus of the bracket was varied approximately up to $\pm 10 \%$. The other properties, such as Poisson's ratio and density, were kept constant throughout the parametric study. Similarly, Young's modulus of the other components was also unchanged. From the complex eigenvalue analysis, it was seen that the anchor bracket had a significant affect on the stability of the system.

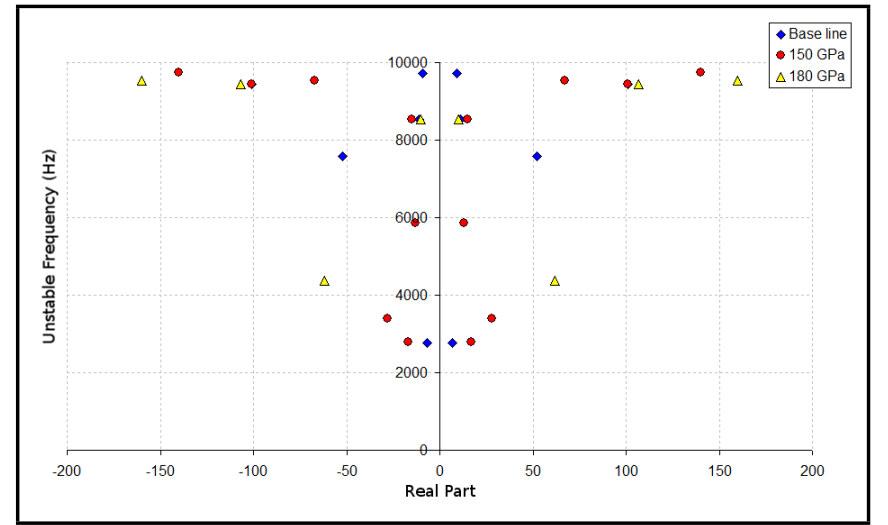

Figure 9. The effect of Young's modulus of the bracket on the brake squeal generation.

As seen in Fig. 9, increasing the modulus to $180 \mathrm{GPa}$ reduced the number of unstable modes to just three. On the other hand, reducing the Young's modulus to $150 \mathrm{GPa}$ had less of an impact with unstable frequencies still present at $2777 \mathrm{~Hz}$, $8530 \mathrm{~Hz}, 9453 \mathrm{~Hz}$, and $9722 \mathrm{~Hz}$. In addition, a new unstable frequencies had appeared in frequencies of $3403 \mathrm{~Hz}, 5873 \mathrm{~Hz}$, and $9530 \mathrm{~Hz}$. Dessouki ${ }^{26}$ concluded that the common countermeasure for caliper bracket induced squeal was to introduce mass loading to the caliper bracket or alternatively to stiffen the bracket. This finding seems to agree with the current simulation results, where was observed that increasing Young's modulus of the anchor bracket may be reducing the brake squeal generation.

\subsection{Influence of Back Plate Young's Modulus}

The disc brake pads consisted of two parts: friction plates, which were made of organic materials, and back plates made of steel. In this study, the baseline Young's modulus of the back plates of the pads was $210 \mathrm{GPa}$. Steel did not show much variation in modulus, but an alternative case was run with the back plates modulus set to $190 \mathrm{GPa}$ and $200 \mathrm{GPa}$. In Fig. 10, it is seen that reducing Young's modulus of the back plate to $190 \mathrm{GPa}$ makes it capable of eliminating positive real parts for unstable frequencies of $2777 \mathrm{~Hz}, 7573 \mathrm{~Hz}$, and $8530 \mathrm{~Hz}$. However, a new unstable mode appeared at approximately $4330 \mathrm{~Hz}$, so the overall noise performance of the system could be significantly improved by reducing the number of unstable frequencies to just three. On the other hand, reducing Young's modulus of the back plate to $200 \mathrm{GPa}$ had less of an impact with unstable frequencies still present at $2777 \mathrm{~Hz}, 7573 \mathrm{~Hz}$, $9453 \mathrm{~Hz}$, and $9722 \mathrm{~Hz}$. However, the unstable frequency of $8530 \mathrm{~Hz}$ was eliminated. Compared to the baseline case, setting back plates modulus to $200 \mathrm{GPa}$ reduced the number of unstable frequencies to just four.

From simulation results, it was observed that the stiffer back plates cause a higher squeal propensity. This was because the friction material connected to the back plates was very soft compared with the back plate material. Hence, the higher stiffness of the back plates, the greater the uneven deformation and vibration magnitude of the pad, and the higher the damping coefficient.

\subsection{Influence of Caliper Young's Modulus}

The base line Young's modulus of the caliper was $171 \mathrm{GPa}$. In this section, the baseline Young's modulus of the caliper 


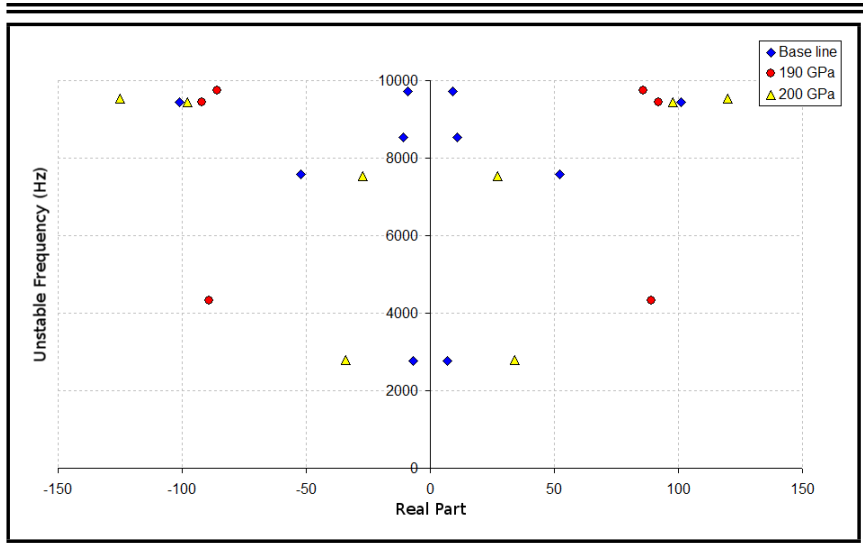

Figure 10. The effect of Young's modulus on the back plate of the brake squeal generation.

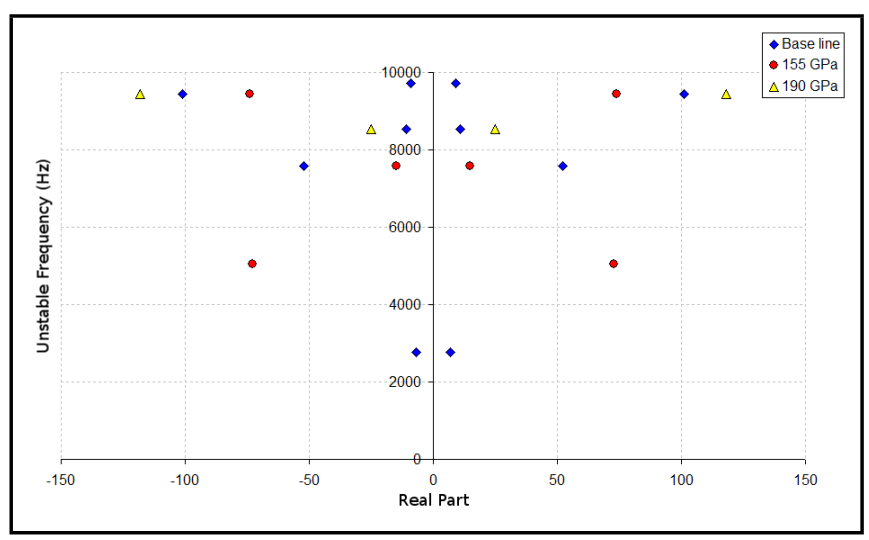

Figure 11. The effect of Young's modulus on the caliper of the brake squeal generation.

was varied approximately up to $\pm 10 \%$. The other properties, such as Poisson's ratio and density, were kept constant throughout the parametric study. Similarly, Young's modulus of other components was also unchanged. Having simulated the variation of Young's modulus of the caliper, it can be seen from Fig. 11 that the caliper also had a significant affect on the stability of the system. Reducing the modulus to $155 \mathrm{GPa}$ reduced the number of unstable modes to just three. On the other hand, increasing Young's modulus of the caliper to $190 \mathrm{GPa}$ was capable of suppressing positive real parts for unstable frequencies of $2777 \mathrm{~Hz}, 7573 \mathrm{~Hz}$, and $9722 \mathrm{~Hz}$. Compared to the baseline case, setting the caliper modulus to $190 \mathrm{GPa}$ reduced the number of unstable frequencies to just two.

In his simulations, Liles ${ }^{7}$ suggested that varying the caliper Young's modulus did not much affect instability of the disc brake model. Additionally, Papinniemi ${ }^{21}$ reported that caliper stiffness may not be beneficial for overall system stability. However, in this study, the resulted show that varying caliper Young's modulus somewhat had an effect on the number of unstable frequencies. By varying this value, it seemed that the unstable frequencies were varied from one to another even though some of them remain.

\subsection{Influence of Steering Knuckle Young's Modulus}

The base line Young's modulus of the steering knuckle was $167 \mathrm{GPa}$. In this section, the baseline Young's modulus of the steering knuckle was varied approximately up to $\pm 10 \%$. The other properties, such as Poisson's ratio and density, were kept

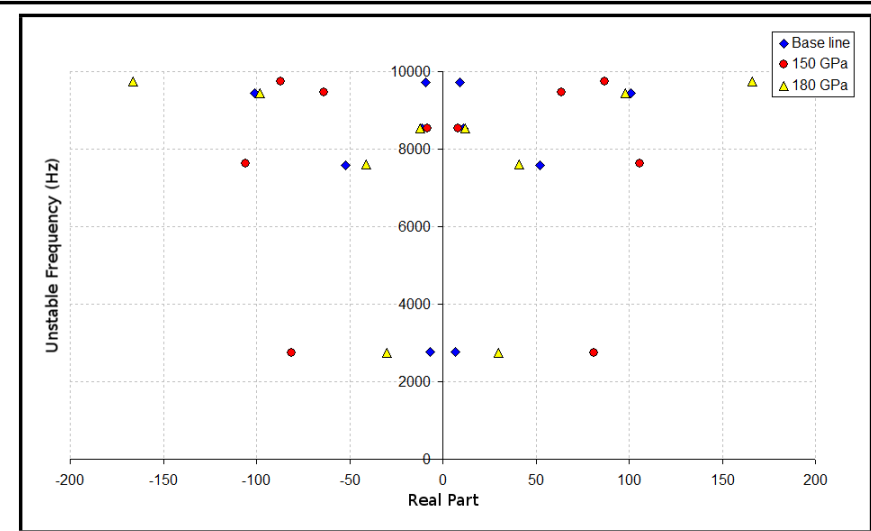

Figure 12. The effect of Young's modulus on the steering knuckle of the brake squeal generation.

constant throughout the parametric study. Similarly, Young's modulus of the other components was also left unchanged. The results in Fig. 12, show real and imaginary parts of the complex eigenvalues when Young's modulus of the friction material varies from $150 \mathrm{GPa}$ to $180 \mathrm{GPa}$. It was found that the number of unstable frequencies was unchanged for varying Young's modulus of the steering knuckle but their magnitudes vary nonlinearly. It was also observed that at frequencies $2777 \mathrm{~Hz}$ and $7573 \mathrm{~Hz}$, increasing Young's modulus of the steering knuckle lead to reduce the real values. However, at frequencies $8530 \mathrm{~Hz}, 9453 \mathrm{~Hz}$, and $9722 \mathrm{~Hz}$ the real parts varied nonlinearly. It was concluded that Young's modulus of the steering knuckle may not be beneficial for overall system stability.

\subsection{Influence of Wheel Hub Young's Modulus}

The base line Young's modulus of the wheel hub was $168 \mathrm{GPa}$. In this section, the baseline Young's modulus of the wheel hub was varied approximately up to $\pm 10 \%$. The other properties, such as Poisson's ratio and density, were kept constant throughout the parametric study. Similarly, Young's modulus of other components was also unchanged. From the complex eigenvalue analysis, it was found that there were unstable frequencies that increased Young's modulus of the wheel hub to $190 \mathrm{GPa}$ and was capable of eliminating positive real parts for unstable frequencies of $2777 \mathrm{~Hz}$ and $8530 \mathrm{~Hz}$. However, a new unstable mode appeared at approximately $5800 \mathrm{~Hz}$. From Fig. 13, setting the wheel hub modulus to $190 \mathrm{GPa}$ reduced the number of unstable frequencies to just four. On the other hand, reducing Young's modulus of the wheel hub to $155 \mathrm{GPa}$ had less of an impact with unstable frequencies still present at $7573 \mathrm{~Hz}, 9453 \mathrm{~Hz}$, and $9722 \mathrm{~Hz}$. However, the unstable frequencies of $2777 \mathrm{~Hz}$ and $8530 \mathrm{~Hz}$ were eliminated. Compared to the baseline case, setting the wheel hub modulus to $155 \mathrm{GPa}$ reduced the number of unstable frequencies to just three. The results of the simulations indicate a range of instability in terms of the wheel hub Young's modulus.

\section{CONCLUSIONS}

This study investigated the effect of Young's modulus variations of the disc brake components on the squeal propensity using a detailed three-dimensional finite element model. Prior to the stability analysis using complex eigenvalue analysis, a 


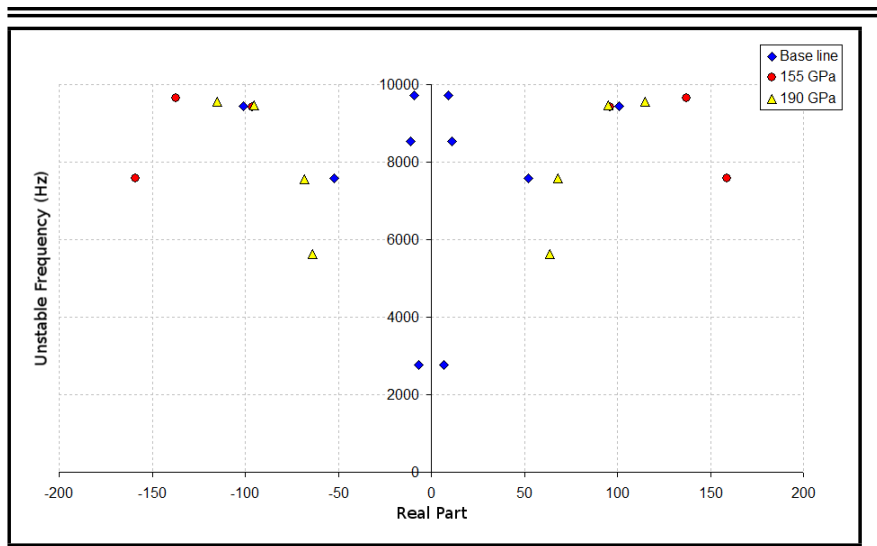

Figure 13. The effect of Young's modulus on the wheel hub of the brake squeal generation.

reasonably agreement is achieved between predicted and experimental results in terms of dynamic characteristics of the developed FE model. The simulation result showed that instability of the disc brake made it sensitive to Young's modulus variations of the disc brake components. It is worth noting that some of those variations reduce the number of unstable frequencies and consequently provide better squeal performance. In particular, increasing Young's modulus of the rotor, friction material, anchor bracket, and back plate. On the other hand, the variations of Young's modulus of the caliper and wheel hub have somewhat effect on the squeal generation. It is also observed that the variation of Young's modulus of the steering knuckle has little influence on the brake to alter its tendency to generate squeal noise.

\section{ACKNOWLEDGEMENTS}

The authors would like to thank Mr. Govardhana Giri of ATALON Testing and Consulting Engineers for his help in conducting modal testing experiments.

\section{REFERENCES}

1 Papinniemi, A., Lai, J. C. S., Zhao, J., and Loader, L. Brake squeal: a literature review, Appl Acoust., 63 (4), 391-400, (2002). http://dx.doi.org/10.1016/s0003-682x(01)00043-3

2 Kinkaid, N. M., O’Reilly, O. M., and Papadopoulos, P. Automotive disc brake squeal, J. Sound Vib., 267 (1), 105-166, (2003). http://dx.doi.org/10.1016/s0022-460x(02)01573-0

3 Nouby, M. G., El-Sharkawy, M., and Ibrahim, A. A Review of Automotive Brake Squeal Mechanisms, J. Mech. Design. Vib., 1 (1), 5-9, (2014).

4 Carlo, C., Riccardo, C., Giampiero, M., Gianpiero, R., and Roberto, S. Brake comfort - a review. Vehicle. Sys. Dyn., 47 (8), 901-947, (2009). http://dx.doi.org/10.1080/00423110903100432

5 Ouyang, H., Nack, W. V., Yuan, Y., and Chen, F. Numerical analysis of automotive disc brake squeal: a review, Int. J Veh. Noise Vib., 1 (3/4), 207-231, (2005). http://dx.doi.org/10.1504/ijvnv.2005.007524

6 Joe, Y. G., Cha, B. G., Sim, H. J., Lee, H. J., and Oh, J. E. Analysis of disc brake instability due to friction-induced vibration using a distributed parameter model, Int. J. Auto. Tech., 9 (2), 161-171, (2008). http://dx.doi.org/10.1007/s12239-008-0021-x

7 Ewins, D. J., Modal testing: theory and practice, Research Studies Press. (2001).

8 Nouby, M., Sujatha, C., and Srinivasan, K. Modelling of Automotive Disc Brake Squeal and Its Reduction Using Rotor Design Modifications, Int. J. Veh Noise. Vib., 7 (2), 129148, (2011). http://dx.doi.org/10.1504/ijvnv.2011.040571

9 Hu, Y., Mahajan, S., and Zhang, K. Brake Squeal DOE Using Nonlinear Transient Analysis, SAE Paper 1999-011737, (1999). http://dx.doi.org/10.4271/1999-01-1737

10 Kung, S. W., Dunlap, K. B., and Ballinger R. S., Complex eigenvalue analysis for reducing low frequency brake squeal, SAE 2000-01-0444, (2000). http://dx.doi.org/10.4271/2000-01-0444

11 Abdo, J., Nouby, M., Mathivanan, D., and Srinivasan, K. Reducing disc brake squeal through FEM approach and experimental design technique, Int. J. Veh. Noise. Vib, 6 (2/3/4), 230-246, (2010). http://dx.doi.org/10.1504/ijvnv.2010.036688

12 Liu, P., Zheng, H., Cai, C., Wang, Y. Y., Lu, C., Ang, K. H., and Liu G. R. Analysis of disc brake squeal using the complex eigenvalue method, Appl Acoust., 68 (6), 603-615,(2007). http://dx.doi.org/10.1016/j.apacoust.2006.03.012

13 Abu-Bakar, A. R. and Ouyang, H. A prediction methodology of disc brake squeal using complex eigenvalue analysis, Int. J. Vehicle Des., 46 (4), 416-435, (2008). http://dx.doi.org/10.1504/ijvd.2008.020307

14 Liles, G. D., Analysis of disc brake squeal using finite element methods, SAE 891150, (1989). http://dx.doi.org/10.4271/891150

15 Lee, Y. S., Brooks, P. C., Barton, D. C., and Crolla D. A., A study of disc brake squeal propensity using a parametric finite element model, In I Mech E Conference Transaction, European Conference on Noise and Vibration, 191201, (1998).

16 Nouby, M., Mathivanan, D., and Srinivasan K. A combined approach of complex eigenvalue analysis and design of experiments (DOE) to study disc brake squeal, Int. J. Eng. Sci. Tech., 1 (1), 254-271, (2009). http://dx.doi.org/10.4314/ijest.v1i1.58084

17 Mario, T. J., Samir, N. Y., and Roberto, J. Analysis of brake squeal noise using the finite element method: A parametric study, Appl Acoust., 69 (2), 147-162, (2008). http://dx.doi.org/10.1016/j.apacoust.2007.10.003

18 Hassan, M. Z., Brooks, P. C., and Barton, D. C. A predictive tool to evaluate disk brake squeal using a fully coupled thermo-mechanical finite element model, Int. J. Vehicle Des, 51 (1/2), 124-142, (2009). http://dx.doi.org/10.1504/ijvd.2009.027118 
Table 5. Comparisons between the predicted results and measured data for brake components.

\begin{tabular}{|c|c|c|c|c|c|}
\hline Components & Mode & Exp. (Hz) & FE $(\mathrm{Hz})$ & Error $(\%)$ & Mode shape \\
\hline \multirow[t]{3}{*}{ Anchor bracket } & 1 & 878 & 880 & 0.2 & \\
\hline & 2 & 1770 & 1755 & -0.8 & \\
\hline & 3 & 3341 & 3164 & -5.2 & \\
\hline \multirow[t]{3}{*}{ Caliper } & 1 & 2282 & 2293 & -1.7 & \\
\hline & 2 & 3769 & 3960 & 5 & \\
\hline & 3 & 5017 & 5182 & 3.2 & \\
\hline \multirow[t]{2}{*}{ Brake Pad } & 1 & 2819 & 2889 & 2.4 & \\
\hline & 2 & 7067 & 6735 & -4.6 & \\
\hline Piston & 1 & 7287 & 7392 & 1.4 & \\
\hline Steering knuckle & 1 & 1232 & 1211 & -1.7 & \\
\hline \multirow[t]{2}{*}{ and wheel hub } & 2 & 2138 & 2242 & 4.8 & \\
\hline & 3 & 4856 & 4421 & 8.9 & \\
\hline
\end{tabular}

19 Dai, Y. and Teik, C. L. Suppression of brake squeal noise applying finite element brake and pad model enhanced by spectral-based assurance criteria, Appl Acoust., 69 (3), 196-214, (2008). http://dx.doi.org/10.1016/j.apacoust.2006.09.010

20 Abu-Bakar, A. R. Modelling and Simulation of Disc Brake Contact Analysis and Squeal, PhD Thesis, Department of Engineering, University of Liverpool, (2005).

21 Papinniemi, A. Vibro-Acoustic Studies of Brake Squeal, PhD Thesis, The University of New South Wales, (2007).

22 Lou, G., Wu, T. W., and Ba, Z. Disk brake squeal prediction using the ABLE algorithm, J Sound Vib., 272 (3/5), 731-748, (2004). http://dx.doi.org/10.1016/s0022$460 \mathrm{x}(03) 00416-4$

23 Fieldhouse, J. D. and Steel, W. P. A study of brake noise and the influence of the centre of pressure at the disc/pad interface, the coefficient of friction and caliper mounting geometry, Proc. I Mech E Part D,
J. Automobile Engineering, 217 (11), 957-973, (2003). http://dx.doi.org/10.1243/095440703770383866

24 Dunlap K. B., Riehle M. A., and Longhouse, R. E. An investigation overview of automotive disc brake noise, SAE Paper 1999-01-0142, (1999). http://dx.doi.org/10.4271/1999-01-0142

25 Lee, Y. S., Brooks, P. C., Barton, D. C., and Crolla, D. A. A Predictive Tool to Evaluate Disc Brake Squeal Propensity Part 3: Parametric Design Study, Int. J. Vehicle Des., 31 (3), 330-353, (2003). http://dx.doi.org/10.1504/ijvd.2003.003364

26 Dessouki, O., Brake, G., Lowe, B., and Chang, W. K. Disc brake squeal: diagnosis and prevention, SAE paper, 200301-1618, (2003). http://dx.doi.org/10.4271/2003-01-1618

\section{APPENDIX A}

Comparisons between the predicted results and measured data for brake components are presented in Table 5. 